\title{
ENSAIOS DE ALTERAÇÃO ACELERADA PARA AVALIAÇÃO DA DURABILIDADE DE SEIS GRANITOS ORNAMENTAIS BRASILEIROS
}

\author{
Javier Eduardo Becerra Becerra ${ }^{1} \&$ Antônio Gilberto Costa ${ }^{2}$
}

RESUMO

\begin{abstract}
As rochas ornamentais experimentam processos de deterioração ocasionados pela poluição atmosférica e por sustâncias industriais usadas nos processos de instalação e manutenção, apresentando perda de brilho, alterações da cor original e redução da resistência mecânica. Os ensaios de alteração acelerada junto com os de caracterização tecnológica, realizados a partir de uma amostragem sistemática nos trabalhos de exploração permitem conhecer antecipadamente a resposta destas rochas face à ação do meio ambiente, podendo se predizer problemas que podem afetar o uso potencial de determinada litologia como rocha ornamental e suas possibilidades de comercialização. Seis variedades de granitos brasileiros foram submetidas a ensaios de lixiviação estática, lixiviação dinâmica, exposição a vapores de ácido sulfuroso e ensaio de cristalização de sais. Todos estes ensaios simulam os principais agentes físicos e químicos que ocasionam deterioração em rochas aplicadas em revestimentos internos e externos. O grau de microfissuramento e a constituição mineralógica foram considerados os fatores petrográficos mais importantes na determinação da alterabilidade. Também foram observadas mudanças nos índices físicos dos granitos mais alteráveis.
\end{abstract}

Palavras-chave: rochas ornamentais, alterabilidade, caracterização tecnológica.

\begin{abstract}
Dimension stone present deterioration caused by air pollution and some industrial substances used for application and maintenance causing loss of brilliance, alterations of original color and reduction of mechanical resistance. The tests of rapid alteration and technological characterization, carried out on base of a systematic sampling during quarrying, permit to establish with anticipation the behavior of rocks against those reagents of environmental conditions, predicting problems that may affect the potential use of determined lithologies as dimension stones and consequently its commerce. Systematic testing of manufactured pieces will increase quality control considerably. Six types of Brazilian granites were submitted to the static lixiviation, exposition to vapors of sulphurous acid and salt crystallization, all of them accelerated alteration tests for simulation of the main chemical and physical agents of deterioration in rocks applied in external and internal revetment. The degree of microfracturing and the mineralogical constitution are the most important petrographic factors of the alterability. A control of technological properties of the materials was also carried out, showing higher alterability of some types.
\end{abstract}

Keywords: Dimension stones, alterability tests, technological characterization.

\section{INTRODUÇÃO}

As rochas ornamentais (granitos, mármores, calcários e outras), são materiais nobres empregados na construção de fachadas, pisos, paredes internas e elementos decorativos que fornecem maior valor agregado às obras onde são usadas. São caracterizados pela durabilidade e boa resistência à agressão do meio ambiente. Porém, quando usadas em ambientes externos, experimentam com maior intensidade os processos de deterioração que aquelas colocadas em ambientes internos. A perda de brilho e alteração da cor original são formas de deterioração que afetam a estética da rocha. Processos de alteração mais intensos geram redução da sua resistência mecânica e durabilidade, ocasionando grandes perdas aos construtores, produtores e comerciantes destes materiais.

$\mathrm{O}$ uso de um material pétreo para fins ornamentais está relacionado com fatores intrínsecos da rocha, tais como intensidade e tipo de alteração, presença de tensões confinadas, heterogeneidade textural e suas propriedades físicas e químicas. Também são importantes os fatores externos, relacionados com os processos de extração e beneficiamento, tais como os defeitos resultantes dos processos de serragem, polimento e brilho que podem ocasionar ou amplificar microfissuras pré-existentes (Aires-Barros, 2001).

Os maciços graníticos, bem como outras jazidas de materiais ornamentais de origem sedimentar ou metamórfica, podem apresentar variações texturais e composicionais, ainda que em distâncias muito pequenas. Isto exige que nos trabalhos de exploração e lavra de rochas ornamentais seja realizada uma amostragem representativa para a execução de ensaios de alteração acelerada e de caracterização tecnológica. Estes ensaios, corretamente interpretados, podem contribuir tanto para a determinação dos setores de uma jazida, que apresentam os melhores materiais para o desenvolvimento de lavra, quanto com a seleção adequada de materiais em relação ao uso, com considerável redução de perdas de material.

As normas internacionais (López, 2002), consideram de fundamental importância a realização dos seguintes ensaios em rochas a serem usadas como materiais de revestimento de fachadas externas, internas e pisos: absorção, peso específico, resistência à flexão, 
resistência ao congelamento e degelo, resistência ao impacto de corpo duro, determinação do coeficiente de absorção por capilaridade, resistência à ancoragem e ensaios de alterabilidade.

A alterabilidade, definida como "a susceptibilidade da rocha a se alterar em função do tempo" (AiresBarros, 2001), é avaliada por meio dos ensaios de alteração acelerada, dentre dos quais a exposição aos vapores de ácido sulfuroso, a lixiviação estática, a lixiviação dinâmica (uso de Extrator Soxhlet) e ensaios de oxidabilidade são muito representativos. Este conjunto de ensaios simula os principais agentes físicos e químicos, que ocasionam deterioração em rochas com aplicação ornamental, entre eles a ação de sustâncias químicas de uso doméstico e industrial, a exposição a ambientes oxidantes (litorâneos) e a condições adversas do meio ambiente (chuva ácida).

Neste trabalho apresentam-se alguns resultados da avaliação da alterabilidade de alguns tipos de granitos ${ }^{1}$ ornamentais, por meio da execução de ensaios orientados a simular os principais processos de ataque químico produzidos por sustâncias presentes nos cenários urbanos afetados por chuva ácida e alta salinidade (ambientes litorâneos) e por sustâncias usadas na instalação e manutenção destes materiais.

\section{MATERIAIS E MÉTODOS}

Após amostragem em afloramentos naturais, lavras ativas e marmorarias, foram realizados ensaios de alteração acelerada no Laboratório de Caracterização Tecnológica de Rochas OrnamentaisLABTECROCHAS do Centro de Pesquisa Manoel Teixeira da Costa/IGC-UFMG, em seis variedades de granitos brasileiros conhecidos com os nomes comerciais de Granito Preto São Gabriel, Granito Verde Pavão, Granito Branco Cotton White, Granito Amarelo Ouro Brasil, Granito Vermelho Capão Bonito e Granito Cinza Prata Imperial.

Antecedendo aos ensaios, foram realizadas as análises petrográficas aplicando a norma EN 12407. Foram realizadas avaliações qualitativas e quantitativas das características petrográficas, relacionadas com a composição mineralógica (Me: minerais esenciais, Mac: minerais acessórios, Ma: minerais de alteração), a textura, o grau ou intensidade de microfissuramento intergranular (It) e intragranular (Ig), a porosidade e a natureza dos contatos intergranulares (planos, côncavo-convexos, serrilhados). Todas estas constituem características que permitem avaliar preliminarmente a susceptibilidade das rochas a se alterar quando as mesmas são usadas em diferentes situações que geram processos de deterioração (Artur et. al., 2001). Das seis variedades de rochas analisadas, cinco correspondem a rochas ígneas plutônicas e uma a rocha metamórfica (granito Amarelo Ouro Brasil). Todas são rochas inequigranulares, de cores diferentes, granulação variável entre meia e grossa e de diferentes composições mineralógicas (Tabela 1).

Tabela 1 - Características petrográficas das rochas submetidas a ensaios de alteração acelerada.

Chapas de $7 \times 7 \times 2 \mathrm{~cm}$

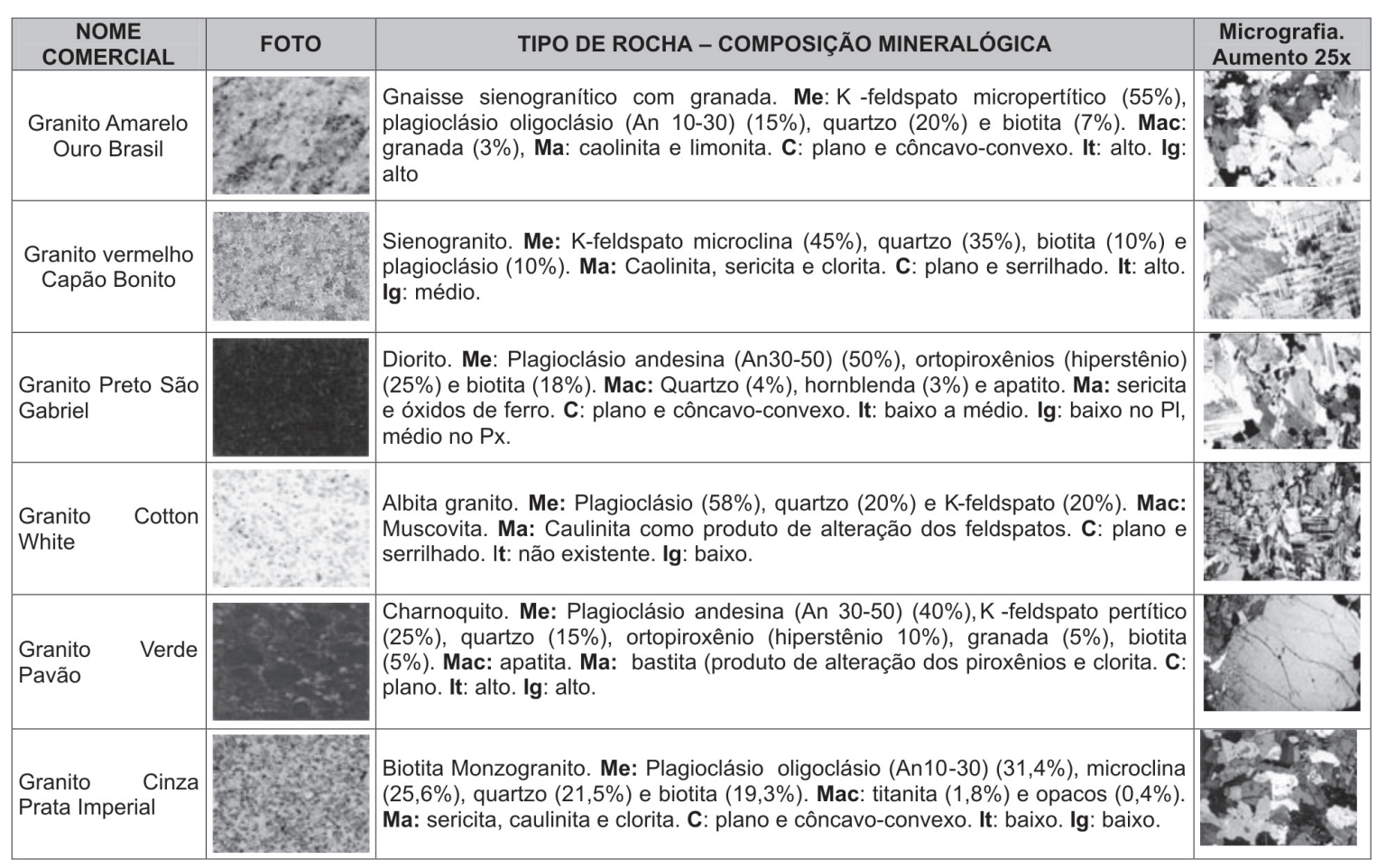

${ }^{1}$ O termo granito é usado aqui com um senso estritamente comercial, não relacionado diretamente com a nomenclatura referente à classificação petrográfica da rocha. 


\section{Ensaios de alteração acelerada}

O conjunto de rochas foi submetido aos ensaios de alteração acelerada, segundo uma seqüência apropriada, com simulação das principais condições a que se encontram expostas, uma vez realizados os processos de beneficiamento.

Os métodos de ensaios seguidos foram os recomendados por normas européias (EN), e brasileiras (ABNT). Alguns ensaios não normalizados foram empregados seguindo métodos utilizados por entidades de pesquisa como o Instituto de Pesquisas Tecnológicas do Estado de São Paulo (IPT), a Universidade Nova de Lisboa (Portugal) e o Laboratório Oficial para Ensaios de Materiais da construção (LOEMCO) da Espanha.

Os ensaios foram realizados expondo tanto a superfície polida da rocha, quanto a superfície sem polir às sustâncias representativas dos agentes causadores de deterioração das rochas ornamentais, utilizando para cada litologia dez corpos de prova de $7 \mathrm{~cm}$ de lado e $2 \mathrm{~cm}$ de espessura.

A oxidabilidade foi avaliada por meio do ensaio de determinação da resistência ao envelhecimento por mudanças térmicas (norma prEN 14066), submetendo os corpos de prova a ciclos sucessivos de aquecimento a $105^{\circ} \mathrm{C}$ seguido de imersão imediata em água a $20^{\circ} \mathrm{C}$. A superfície das chapas também foi exposta à ação de solução de peróxido de hidrogênio com uma concentração de 50\% (Becerra-Becerra \& Costa., 2005). Esta sustância além de ser fortemente oxidante, permite diferenciar as rochas porosas das não porosas, devido à intensidade do ataque que pode ser muito forte, ocasionado às vezes a desintegração da rocha (Lombardero, 2001 in Calvo \& Maya, 2001).

A simulação da exposição das rochas às sustâncias químicas presentes no meio ambiente urbano poluído, foi feita através do ensaio de lixiviação estática, denominado pelo IPT como "ensaio de alterabilidade por imersão em líquidos reativos", no qual as amostras são imersas nas soluções reagentes de $\mathrm{HCl}, \mathrm{H}_{2} \mathrm{SO}_{4}$ e $\mathrm{HNO}_{3}$ diluídas até $\mathrm{pH}=3$, por um período de 20 dias (Becerra-Becerra \& Costa, 2003). Também foi realizado o ensaio de Resistência ao Envelhecimento por $\mathrm{SO}_{2}$ (norma EN 13919), expondo os corpos de prova a vapores de ácido sulfuroso em câmara fechada.

Os ensaios foram realizados expondo tanto a superfície polida da rocha, quanto a superfície sem polir às sustâncias representativas dos agentes causadores de deterioração das rochas ornamentais, utilizando para cada litologia dez corpos de prova de $7 \mathrm{~cm}$ de lado e 2 $\mathrm{cm}$ de espessura.

O ensaio de cristalização de sais (norma EN12370), por meio de ciclos de imersão das rochas em solução de sulfato de sódio anidro (14\% p/p) seguida de secagem em estufa, permitiu verificar o efeito das argamassas usadas na instalação das peças terminadas e a resistência oferecida pelos materiais.

Foi realizado o controle das mudanças estéticas e da variação de massa nos corpos de prova. Para os granitos que apresentaram maior deterioração física (mudança de tonalidades, perda de brilho, etc), além de registrar a variação de massa, foram determinados os índices físicos, observando a variação destes parâmetros por efeito da alterabilidade dos materiais. Por meio da petrografia, realizada antes e depois dos ensaios, observaram-se as mudanças ocorridas na microfissuração, na aparência superficial dos minerais, nos contornos cristalinos etc. Nas chapas com acabamento, determinou-se a formação de manchas, áreas com oxidação notória, perda ou variação do brilho etc.

Os líquidos residuais foram analisados por plasma, visando a determinação de perdas de cátions nos minerais, as quais ocasionam problemas de deterioração e mudanças físicas na rocha. Para complementar o conjunto de análises realizadas, utilizou-se o microscópio eletrônico de varredura com microssonda acoplada (MEV-EDS) para observação de mudanças acontecidas na superfície dos minerais, as variações em nível de microfissuras e poros, o efeito da cristalização de sais na estrutura interna da rocha e a neoformação de minerais.

\section{RESULTADOS E DISCUSSÃO}

Apresentam-se as observações registradas tanto na superfície das rochas, quanto aquelas ocorridas a nível mineralógico depois dos ensaios de alteração acelerada.

\section{Mudanças na aparência estética das chapas}

Dentre as mudanças estéticas observadas, destacamse a perda de brilho e o realce de algumas características como o microfissuramento, especialmente nos granitos Verde Pavão e Preto São Gabriel (Figura 1).

No granito Verde Pavão, ocorrem importantes danificações na sua aparência e estrutura. A cor original verde oliva intenso mudou para uma tonalidade verde clara, com formação de superfícies esbranquiçadas em alguns setores. Observou-se também o realce do microfissuramento existente, a geração de pequenas cavidades e a perda significativa do brilho original. $\mathrm{O}$ Granito Preto São Gabriel apresentou perda relativa de brilho, mas a mudança mais significativa registrase na tonalidade de cor que passou de negra intensa a cinza intermediária, com desenvolvimento de manchas amareladas ao redor dos cristais de biotita (BecerraBecerra, 2004).

No granito Amarelo Ouro Brasil, os ensaios de alteração acelerada permitiram observar a formação de manchas amareladas de oxidação nas bordas dos cristais de granada (almandina), devidas à oxidação e liberação do ferro constituinte deste mineral. O manchamento é mais acentuado quando a sustância utilizada para o ataque ácido é o $\mathrm{HCl}$ (Figura 2). As demais áreas, correspondentes aos minerais de feldspatos não experimentaram mudanças significativas.

O granito Vermelho Capão Bonito apresenta uma leve mudança de tonalidade de cor original de vermelho a rosa escuro, sem perda do brilho original. 

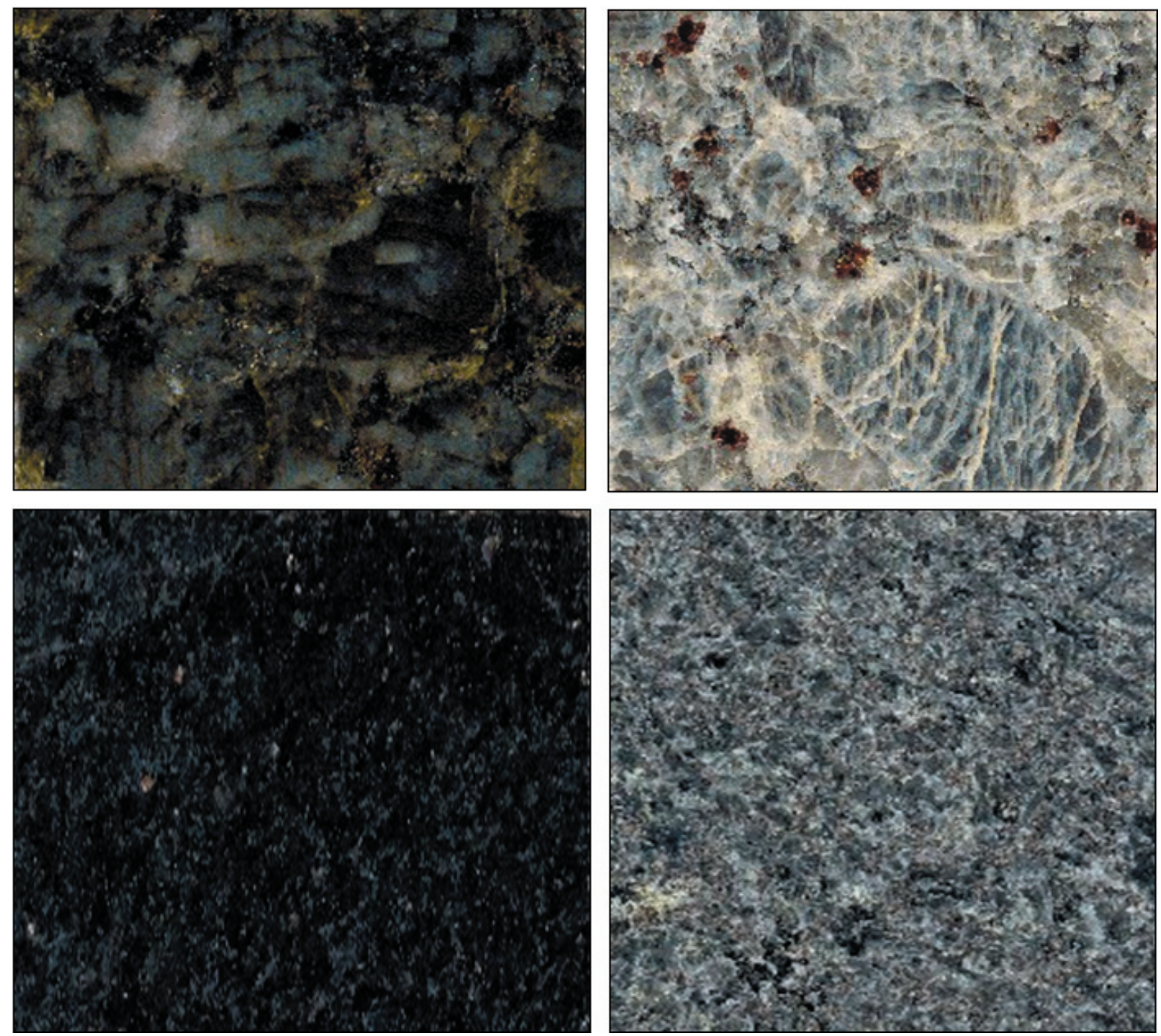

Figura 1 - Mudanças estéticas ocorridas nos granitos Verde Pavão (superior) e Preto São Gabriel (inferior) depois da execução dos ensaios de alterabilidade. Chapas de $7 \times 7 \times 2 \mathrm{~cm}$.

Os granitos Cinza Prata Imperial e Cotton White não apresentam mudanças estéticas significativas.

\section{Observações ao microcópio petrográfico em relação ao microfissuramento e a aparência dos minerais}

A análise petrográfica ajudou a corroborar as observações feitas nas chapas submetidas aos ensaios de alteração acelerada. A resposta dos granitos face ao tratamento com ácido foi semelhante para as diferentes soluções, observando-se alteração progressiva dos minerais e o crescimento gradual das microfissuras, especialmente nos cristais de plagioclásio. Foi observado o microfissuramento como fator facilitador dos processos de alteração, nos granitos Amarelo Ouro Brasil e Verde Pavão. A alteração mineralógica foi observada, especialmente nos cristais de plagioclásio com maior conteúdo de cálcio (An30-50), constituintes do granito Preto São Gabriel, que apresentam a superfície mais suja em relação com a aparência na lâmina da rocha não atacada, com desenvolvimento de novas microfissuras e crescimento das já existentes (Figura 3). Alterações menores foram observadas nos cristais de piroxênio, destacando-se as mudanças nas cores de interferência dos minerais (Becerra-Becerra, 2004).

No granito Amarelo Ouro Brasil desenvolveramse superfícies de alteração, especialmente nos cristais de granada, mineral responsável em grande parte pela liberação de ferro; verificou-se ainda alteração nos cristais de feldspatos, que aparecem nalâmina alterada com aparência suja e maior desenvolvimento de microfissuras.

No granito Verde Pavão, a clorita presente nas microfissuras é removida e observa-se alteração dos cristais de piroxênio, plagioclásio e em menor proporção de K-feldspato. Os feldspatos mudam de coloração, passando de tonalidades esverdeadas nos cristais sãos, a amarelos nos feldspatos alterados. Igualmente ocorre aumento do espaçamento das microfissuras (Figura 4).

Os granitos Vermelho Capão Bonito, Branco Cotton White e Cinza Prata Imperial 

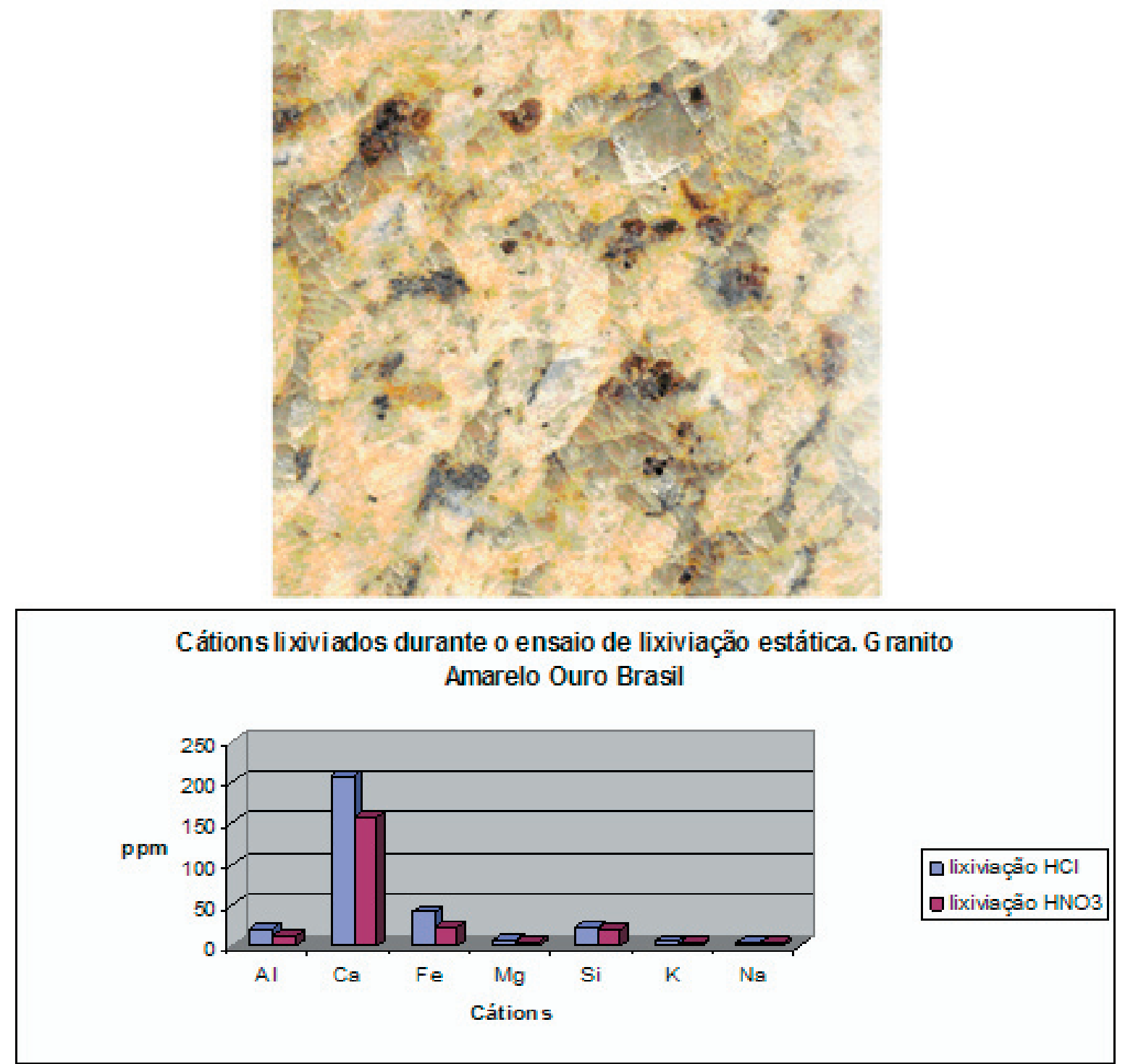

Figura 2. Oxidação dos cristais de granada (manchas amareladas) no granito Ouro Brasil depois do ensaio de lixiviação estática. À direita, relação dos elementos lixiviados (ppm) determinados com Espectrômetro de Plasma Indutivo AES. Chapa de $7 \times 7 \times 2 \mathrm{~cm}$.

apresentaram poucas mudanças a nível micros cópico,restringidas a uma incipiente alteração dos cristais de K-feldspato e de plagioclásio.

\section{Perdas de massa e mudanças nos índices físicos}

Além das observações feitas nas chapas e nas lâminas petrográficas, as amostras submetidas aos ensaios de envelhecimento acelerado, foram pesadas antes e depois dos ensaios para verificar a variação de massa. A perda de massa, definida como a variação percentual da massa depois dos ensaios em relação com a massa inicial, representa a quantidade de material dissolvido, devido aos processos de lixiviação ocasionada pelas sustâncias reagentes. Todos os granitos experimentaram perda de massa (Tabela 2), mas esta é mais significativa nos granitos Preto São Gabriel e Verde Pavão. Perdas equivalentes à metade das acontecidas para os dois granitos mencionados ocorrem nos granitos Vermelho Capão Bonito, Cinza Prata Imperial e Amarelo Ouro
Brasil. No granito Branco Cotton White, a perda de massa não foi significativa.

A análise por meio do Espectrômetro de Plasma Indutivo-AES das soluções, após realizados os ensaios de alteração acelerada, permitiu determinar os cátions lixiviados durante o processo e responsáveis pelas perdas de massa ocorridas (Tabela 3).

Para os granitos que registraram as maiores mudanças nos ensaios de alteração acelerada (Preto São Gabriel e Verde Pavão) foram avaliados os índices físicos (norma NBR 12766) com determinação da: massa específica aparente ou densidade aparente seca, peso específico aparente saturado ou densidade aparente saturada, porosidade aparente (\%) e percentagem de absorção de água, depois dos ensaios de lixiviação (Tabela 4). Os valores obtidos foram comparados com os valores registrados nos materiais inalterados com a determinação das variações devidas à perda ou lixiviação mineralógica.

É conhecida a relação inversa entre a massa 

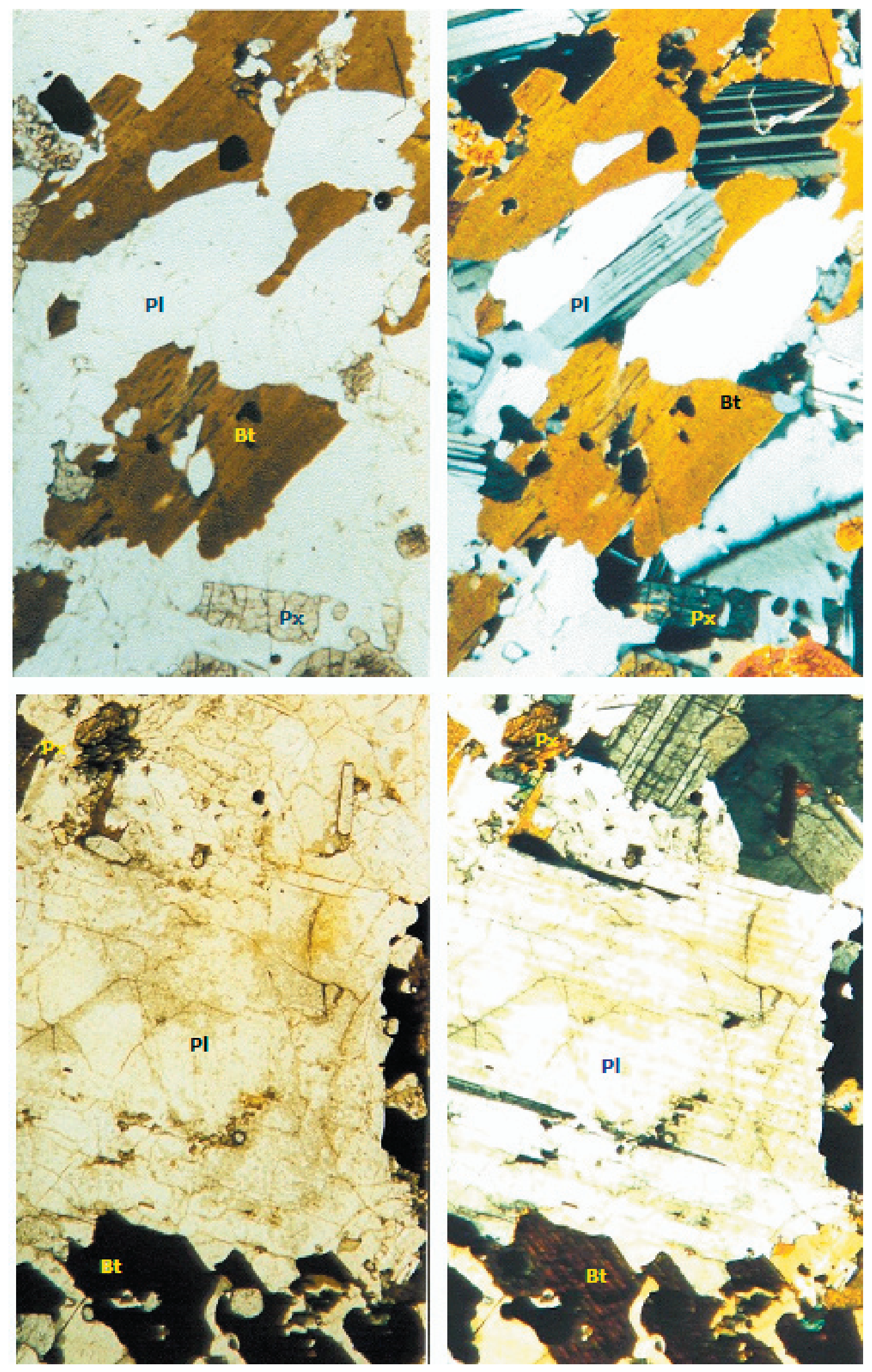

Figura 3 - Alteração do granito Preto São Gabriel. Ensaio de lixiviação estática com solução de $\mathrm{H}_{2} \mathrm{SO}_{4}$.

Foto Superior: imagem de chapa inalterada. Foto Inferior: imagem de chapa depois do ataque ácido.

Observa-se mudança de tonalidade, intensificação do microfissuramento e alteração superficial do plagioclásio. (Pl) plagioclásio, (Bt) biotita, (Px) piroxênio. Esquerda nicóis paralelos; direita nicóis cruzados. Aumento $25 X$. 

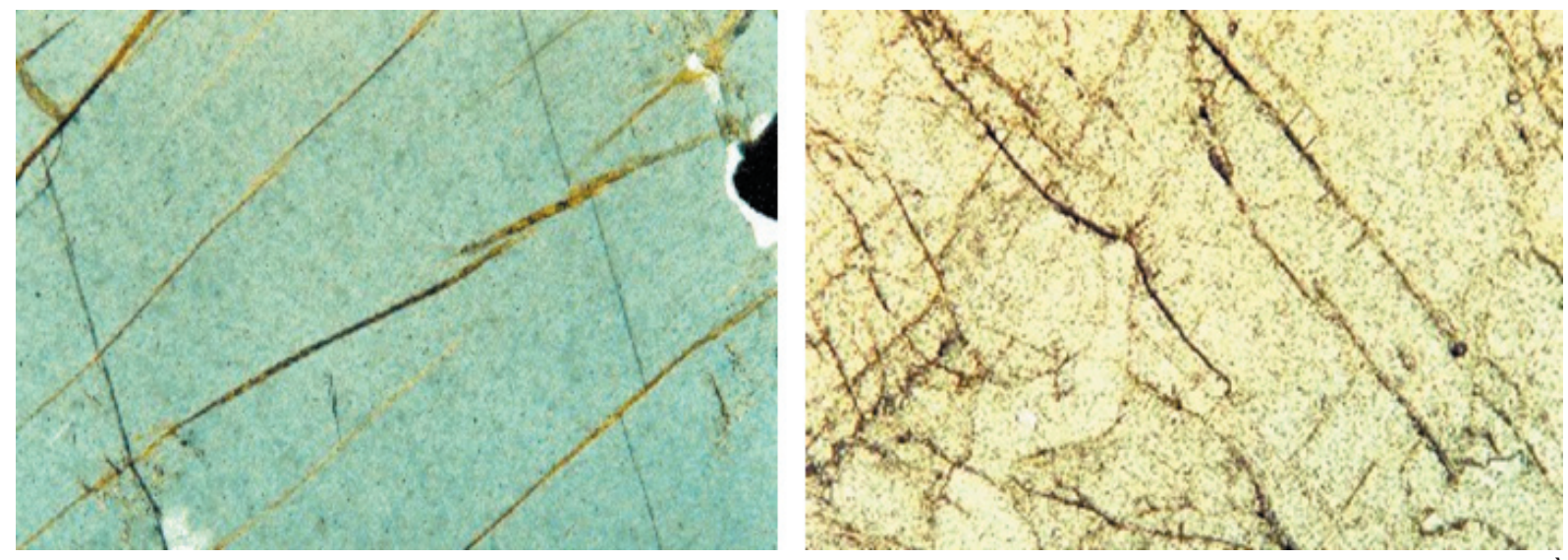

Figura 4 - Mudanças no nível de microfissuramento e cor dos cristais de K-feldspato no Granito Verde Pavão. À esquerda (chapa inalterada), cor verde e fraturas com preenchimento de clorita e de óxidos.

À direita (chapa alterada), a cor muda para amarelo, apresenta-se deterioração da superfície dos cristais e não se observa o material de preenchimento das fissuras. Nícois cruzados. Aumento $100 X$.

Tabela 2 - Exemplo de Perda de massa para um corpo de prova das diferentes litologias após os ensaios de lixiviação estática. Solução reagente $\mathrm{HCl}$ (concentração 0,25\% v/v)

\begin{tabular}{|c|c|c|c|c|}
\hline Litologia & $\begin{array}{c}\text { Massa } \\
\text { Inicial }(g)\end{array}$ & $\begin{array}{c}\text { Massa } \\
\text { Final }(\mathrm{g})\end{array}$ & $\begin{array}{c}\text { Diferença } \\
\text { de massa } \\
(\mathrm{g})\end{array}$ & Perda (\%) \\
\hline $\begin{array}{r}\text { Granito Preto São } \\
\text { Gabriel }\end{array}$ & 361,52 & 360,29 & 1,23 & 0,34 \\
\hline Granito Verde Pavão & 544,5 & 543,13 & 1,37 & 0,25 \\
\hline $\begin{array}{l}\text { Granito Vermelho } \\
\text { Capão Bonito }\end{array}$ & 231,9 & 231,87 & 0,03 & 0,12 \\
\hline $\begin{array}{l}\text { Granito Cinza Prata } \\
\text { Imperial }\end{array}$ & 502,82 & 502,23 & 0,59 & 0,11 \\
\hline $\begin{array}{r}\text { Granito Amarelo Ouro } \\
\text { Brasil }\end{array}$ & 488,79 & 488,29 & 0,50 & 0,10 \\
\hline Granito Cotton White & 529,02 & 528,74 & 0,28 & 0,05 \\
\hline
\end{tabular}

Tabela 3 - Elementos lixiviados durante o ensaio de lixiviação estática. Solução reagente $\mathrm{HCl}$

\begin{tabular}{|c|c|c|c|c|c|c|c|}
\hline Litologia & $\begin{array}{c}\mathbf{A l} \\
(\mathbf{p p m})\end{array}$ & $\begin{array}{c}\mathbf{C a} \\
(\mathbf{p p m})\end{array}$ & $\begin{array}{c}\mathbf{F e} \\
(\mathbf{p p m})\end{array}$ & $\begin{array}{c}\mathbf{M g} \\
(\mathbf{p p m})\end{array}$ & $\begin{array}{c}\mathbf{S i} \\
(\mathbf{p p m})\end{array}$ & $\begin{array}{c}\mathbf{K} \\
(\mathbf{p p m})\end{array}$ & $\begin{array}{c}\mathbf{N a} \\
(\mathbf{p p m})\end{array}$ \\
\hline $\begin{array}{c}\text { Granito Preto São } \\
\text { Gabriel }\end{array}$ & 35,0 & 516 & 163 & 108 & 73,2 & 30 & 8 \\
\hline $\begin{array}{c}\text { Granito Verde } \\
\text { Pavão }\end{array}$ & 36,0 & 145 & 422 & 46,0 & 40,4 & 13 & 4 \\
\hline $\begin{array}{c}\text { Granito Amarelo } \\
\text { Ouro Brasil }\end{array}$ & 20,2 & 207 & 41,1 & 7,8 & 21,3 & 6 & 4 \\
\hline $\begin{array}{c}\text { Granito Cinza } \\
\text { Prata Impe rial }\end{array}$ & 58,9 & 427 & 103 & 36,4 & 68,3 & 50 & 5 \\
\hline $\begin{array}{c}\text { Granito Vermelho } \\
\text { Granito Branco } \\
\text { Cotton White }\end{array}$ & 54,8 & 133 & 169 & 15,1 & 46,2 & 30 & 2 \\
\hline
\end{tabular}


Tabela 4 - Variação dos índices físicos dos granitos Preto São Gabriel e Verde Pavão após o ensaio de lixiviação estática

\begin{tabular}{|c|c|c|c|c|c|}
\hline \multicolumn{6}{|c|}{ Índices Físicos } \\
\hline \multicolumn{2}{|c|}{ Litologia } & $\begin{array}{c}\text { Massa } \\
\text { específica } \\
\text { aparente }\end{array}$ & $\begin{array}{c}\text { Massa } \\
\text { específica } \\
\text { aparente }\end{array}$ & $\begin{array}{c}\text { Porosidade } \\
\text { aparente } \\
(\%)\end{array}$ & $\begin{array}{c}\text { Absorção } \\
\text { de água } \\
\text { aparente }\end{array}$ \\
\hline \multirow{2}{*}{$\begin{array}{c}\text { Preto São } \\
\text { Gabriel }\end{array}$} & $\begin{array}{c}\text { Antes do } \\
\text { ensaio }\end{array}$ & 2,958 & 2,963 & 0,462 & 0,156 \\
\hline & $\begin{array}{c}\text { Depois do } \\
\text { ensaio }\end{array}$ & 2,954 & 2,959 & $0,5 \quad 73$ & 0,194 \\
\hline \multirow{2}{*}{$\begin{array}{l}\text { Verde } \\
\text { Pavão }\end{array}$} & $\begin{array}{c}\text { Antes do } \\
\text { ensaio }\end{array}$ & 2,713 & 2,723 & 0,497 & 0,167 \\
\hline & $\begin{array}{c}\text { Depois do } \\
\text { ensaio }\end{array}$ & 2,701 & 2,709 & 0,569 & 0,199 \\
\hline
\end{tabular}

específica aparente e os parâmetros de porosidade e o coeficiente de absorção de água. Para um mesmo tipo de rocha, quanto maior é a massa específica aparente, menor será a porosidade e o coeficiente de absorção de água. Pelo contrário, quanto menor é a massa específica aparente, maior é a porosidade e o coeficiente de absorção de água (López et al., 1996).

As mudanças nos índices físicos das rochas, devidas à presença de minerais alterados ou susceptíveis de experimentar alteração, estão diretamente relacionadas com a diminuição progressiva da sua resistência mecânica que incide na perda da vida útil da rocha, especialmente quando são expostas a ambientes úmidos ou contaminados, desenvolvendo processos de alteração ainda mais intensos.

\section{Observações ao microscópio eletrônico de} varredura MEV em relação ao microfissuramento e à porosidade

Observações ao microscópio eletrônico de varredura MEV permitiram corroborar as mudanças já determinadas no microscópio petrográfico em relação ao micro-fissuramento (Becerra-Becerra \& Costa 2005). Foi possível observar importante aumento do espaçamento das microfissuras após os ensaios de alterabilidade e a geração de novas fissuras interconectadas, tanto intergranulares quanto intragranulares nos cristais de piroxênio e plagioclásio. Também foi observada a corrosão nas bordas dos cristais de biotita (Figura 5).

Com o uso do MEV também foi possível observar os efeitos produzidos pela cristalização de sais solúveis nas rochas, de forma semelhante aos gerados pela formação de gelo nos poros (Figura 6). Os sais podem ser provenientes das argamassas usadas na instalação, dos materiais usados nos processos de restauração ou conservação da pedra natural, ou também, provenientes do solo, por ascensão capilar. Podem estar em solução, seja de forma insaturada, saturada ou sobre-saturada. O passo de um estado para outro pode se produzir pela adição de sal, pela evaporação de água ou pela variação de temperatura.

Quando no interior do material poroso existe uma solução salina, o fenômeno de cristalização nos espaços capilares será inevitável, gerando-se uma pressão sobre as paredes ou ao longo da estrutura do próprio material, que será maior quanto mais elevada for a sua concentração (LÓPEZ J.C, et.al., 1996). Os sais podem exercer forças de expansão devido à cristalização,
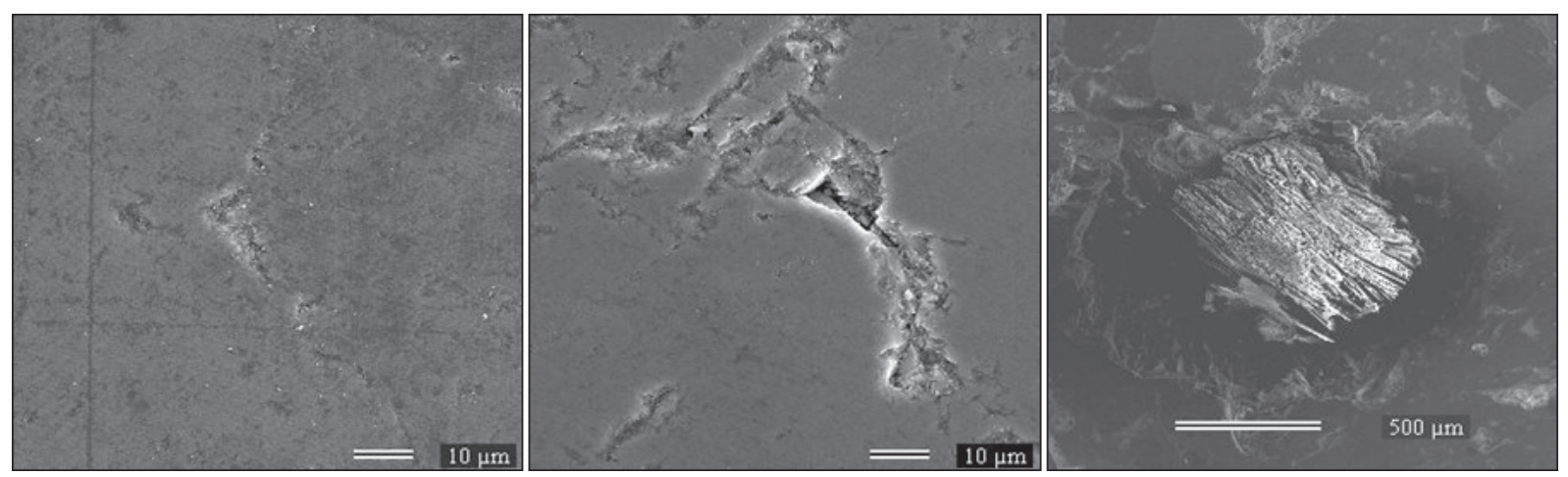

Figura 5 - Detalhe do microfissuramento dos cristais de plagioclásio antes (esquerda) e depois (centro) dos ensaios de alteração acelerada. Observa-se acréscimo importante na quantidade de microfissuras e nas dimensões das já existentes. Corrosão das bordas dos cristais de biotita (direita). Granito Preto São Gabriel. 

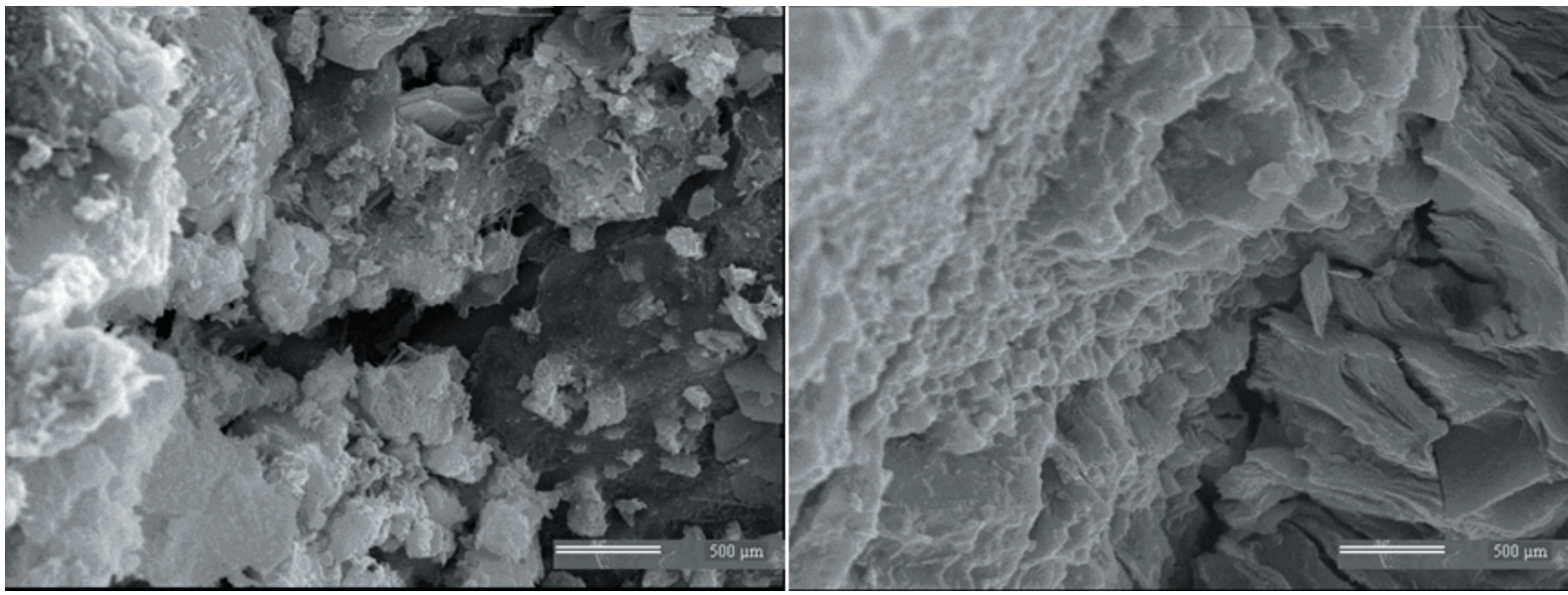

Figura 6-Imagens de MEV mostrando o efeito da cristalização de sais no interior das microfissuras em um cristal de plagioclásio (Granito Verde Pavão). À esquerda, observa-se cristalização incipiente.

A direita, o mesmo processo em um estado avançado.

semelhantes às desenvolvidas pelo congelamento das águas intersticiais, as quais são capazes de provocar a fragmentação de minerais adjacentes, de forma lenta e progressiva podendo inclusive romper por completo as chapas.

Em relação aos resultados do ensaio de cristalização de sais, observou-se maior concentração e cristalização nos granitos cujos cristais de quartzo e plagioclásio são de maior tamanho (Granitos Ouro Brasil e Verde Pavão). Estes minerais correlacionam-se com a absorção de forma linearmente positiva. A explicação (Bezerra de Melo \& Da Costa, 2002), está na facilidade de fsissuramento sob pressão que apresenta o quartzo e a alterabilidade do plagioclásio, fatores estes que facilitam a formação de poros e microfissuras. Nos outros granitos ensaiados não foram observados processos importantes de cristalização de sais.

\section{Discussão de resultados em relação aos ambientes de aplicação}

De acordo com os resultados obtidos nos ensaios de alteração acelerada, não é recomendável o uso dos granitos "Preto São Gabriel" e "Verde Pavão" para o revestimento de fachadas ou de pisos externos. Estes granitos podem ser melhor aproveitados como elementos decorativos internos, que não estejam expostos à ação da contaminação do medio ambiente $\mathrm{e}$ não precisem de constantes processos de limpeza.

Em relação com o granito amarelo "Ouro Brasil", este material deve ser usado com precaução em ambientes externos, procurando o uso de sustâncias hidro-repelentes apropriadas, que evitem ou minimizem os efeitos da oxidação dos cristais de granada.

Do grupo de granitos avaliados, os mais apropriados para o uso en revestimentos externos são os de composição quartzo-feldspática, neste caso o Granito Vermelho Capão Bonito. Também podem ser utilizados os que apresentam menor grau de microfissuramento e baixa proporção de minerais susceptíveis a alteração.
Do conjunto ensaiado, cumprem com estas condições o Granito Cinza Prata Imperial e o Branco Cotton White, os quais também são recomendados para o uso em pisos internos e acabamentos que requerem limpeza freqüente (por exemplo, peças de mesas, banheiros etc).

Os Granitos Verde Pavão, Amarelo Ouro Brasil e Preto São Gabriel, devido ao seu alto valor comercial, devem ser usados, preferivelmente em paredes e pisos internos, que tenham baixo tráfico de pedestres e como elementos decorativos que não precisem de limpeza constante, evitando assim, a deterioração causada pelo uso de sustancias industriais.

\section{CONCLUSÕES}

Os ensaios de alteração acelerada cumprem com o objetivo de avaliar, antecipadamente, os processos de deterioração resultantes da aplicação de rochas ornamentais, em ambientes externos e internos, quando usados como revestimentos, pisos ou elementos estruturais e decorativos, seja em locais comerciais ou residenciais. Os ensaios efetuados permitem uma visão global em relação à resposta que as rochas apresentarão quando expostas aos principais agentes físicos e químicos que as degradam.

Os ensaios de alteração acelerada realizados nos granitos avaliados permitiram determinar a alterabilidade de maior para menor grau, segundo a seguinte ordem: Granito Preto São Gabriel > Granito Verde Pavão $>$ Granito Amarelo Ouro Brasil $>$ Granito Cinza Prata Imperial $>$ Granito Vermelho Capão Bonito $>$ Granito Blanco Cotton White.

A alterabilidade do Granito Preto São Gabriel está condicionada essencialmente à composição mineralógica. Nos demais granitos avaliados ela obedece a dois fatores principais: composição mineralógica e grau de microfissuramento.

Considerando que as sustâncias utilizadas no ensaio encontram-se no ar de ambientes urbanos e litorâneos e são constituentes da chuva ácida, a resposta dos granitos 
Preto São Gabriel, Verde Pavão e Amarelo Ouro Brasil indicam que não é conveniente o uso destas litologias em revestimentos externos.

\section{AGRADECIMENTOS}

Os autores agradecem à FAPEMIG pelo financiamento da pesquisa através dos projetos CRA 247/97 e, ao CNPq pela concessão da bolsa de doutoramento ao primeiro autor e ao Laboratório de Caracterização Tecnológica de Rochas Ornamentais (LABTECROCHAS) - CPMTC/IGC/UFMG pelo apoio na execução dos ensaios.

\section{REFERÊNCIAS BIBLIOGRÁFICAS}

Aires-Barros, L. (2001). "As rochas dos monumentos portugueses Tipologias e patologias”. Volumen 1. Lisboa. Instituto Português do Patrimônio Arquitetônico. 590p.

Associação Brasileira de Normas Técnicas - ABNT.(1992). Rochas para revestimento. Determinação da massa específica aparente, porosidade aparente e absorção d'água aparente. Norma NBR 12766. 8p.

Artur, A. C., Meyer, A.,Wernick, E. (2001). Características tecnológicas de granitos ornamentais: a influência da mineralogia textura e estrutura da rocha. Dados comparativos e Implicações de utilização. In Anais.. I Simpósio Brasileiro de Rochas Ornamentais. Salvador - Bahia. p. 13-19.

Becerra Becerra, J.E \& Costa, A. G. (2005). Avaliação do grau de oxidabilidade de rochas graníticas com aplicação ornamental. In Anais.. Primeiro Congresso Internacional de rochas ornamentais. CD-ROM, CETEM. Rio de Janeiro.
Becerra Becerra, J.E. (2004). “Alterabilidade de rochas com aplicação ornamental: procedimentos analíticos para sua avaliação". Dissertação de Mestrado em Geologia econômica e aplicada. IGC-UFMG. 117p.

Becerra Becerra, J.E., Costa, A.G. (2003). Procesos de alterabilidad en granitos ornamentales brasileños. Diagnóstico y técnicas de evaluación. In Memorias.. IX Congreso Colombiano de Geología. Medellín-Colombia. p. 275-278.

Bezerra de Melo, E \& da Costa, F. M.O. (2002). Escolha de tipos texturais de rochas e sua aplicação ornamental. In Anais.. III Simpósio de Rochas Ornamentais do Nordeste. CD-ROM, CETEM. Rio de Janeiro.

Calvo, B \& Maya Sanchez, M. (2001). Avanços e Transferência Tecnológica em Rocha Ornamental. Série Rochas e Minerais Industriais. CETEM. 183p.

European Committee for Standarization CEN.(2000). Natural Stone Test Methods. Petrographic examination. Norma EN 12407. 8 p.

European Committee For Standarization CEN.(1999). Natural Stone Test Methods. Determination of resistance to salt crystallization. Norma EN12370. 7p

European Committee for Standarization CEN.(2002). Natural Stone Test Methods. Determination fo resistance to ageing by thermal shock. Final Draft. Norma prEN 14066. 8p.

European Committee for Standarization CEN.(2002). Natural Stone Test Methods. Determination fo resistance to ageing by $\mathrm{SO}_{2}$ action in the presence of humidity. Final Draft. Norma EN 13919. 7p.

López González-Mesones, F. (2002). La interpretación de los ensayos de caracterización de la piedra natural en el marco de la nueva normativa europea. In Anais .. III Simposio de Rochas Ornamentais do Nordeste. Curso de rochas ornamentais para projetos arquitetônicos e urbanísticos. CD-ROM, CETEM. Rio de Janeiro.

López, J.C. et.al., 1996. Manual de Rocas Ornamentales. Madrid. Editora Entorno Gráfico, S.L. 695p. 